\title{
Understanding the Impact of Business Analytics on Innovation
}

\author{
Yanqing Duan* \\ Business School, University of Bedfordshire, Luton, LU1 3JU \\ yanqing.duan@beds.ac.uk \\ Guangming Cao \\ Business School, University of Bedfordshire, Luton, LU1 3JU \\ guangming.cao@beds.ac.uk \\ John S. Edwards \\ Aston Business School, Aston University, Birmingham, B4 7ET \\ j.s.edwards@aston.ac.uk
}

*- Corresponding author

Professor Yanqing Duan

Business School,

University of Bedfordshire,

Luton, LU1 3JU

Yanqing.duan@beds.ac.uk

Tel: +44( 0) 1582743134 


\title{
Understanding the Impact of Business Analytics on Innovation
}

\begin{abstract}
Advances in Business Analytics in the era of Big Data have provided unprecedented opportunities for organizations to innovate. With insights gained from Business Analytics, companies are able to develop new or improved products/services. However, few studies have investigated the mechanism through which Business Analytics contributes to a firm's innovation success. This research aims to address this gap by theoretically and empirically investigating the relationship between Business Analytics and innovation. To achieve this aim, absorptive capacity theory is used as a theoretical lens to inform the development of a research model. Absorptive capacity theory refers to a firm's ability to recognize the value of new, external information, assimilate it and apply it to commercial ends. The research model covers the use of Business Analytics, environmental scanning, data-driven culture, innovation (new product newness and meaningfulness), and competitive advantage. The research model is tested through a questionnaire survey of 218 UK businesses. The results suggest that Business Analytics directly improves environmental scanning which in turn helps to enhance a company's innovation. Business Analytics also directly enhances data-driven culture that in turn impacts on environmental scanning. Data-driven culture plays another important role by moderating the effect of environmental scanning on new product meaningfulness. The findings demonstrate the positive impact of business analytics on innovation and the pivotal roles of environmental scanning and data-driven culture. Organizations wishing to realize the potential of Business Analytics thus need changes in both their external and internal focus.
\end{abstract}

\section{Keywords}

Analytics; Innovation; Big Data; Data-Driven Culture; Absorptive Capacity. 


\section{Introduction}

Organizations need to innovate in response to changing customer demands and opportunities offered by technology and changing marketplaces, structures and dynamics (Baregheh, Rowley, \& Sambrook, 2009). Joshi, Chi, Datta, and Han (2010) examine the relationship between IT and firm innovation focusing on knowledge capabilities that are enhanced through the use of IT, and demonstrate that IT plays a significant role in enhancing firm innovation. The combination of Big Data and Business Analytics (BA) represents one of the latest opportunities for organizations to change their practices by the use of IT (Goes, 2014). It is argued that organizations need to act swiftly to benefit from Big Data and BA by using them to create innovation and competitive advantage.

The concept of Business Analytics (BA) is not new, but has recently re-emerged as an important area of study owing to its developing capabilities to handle Big Data (Chen, Chiang, \& Storey, 2012; Watson, 2014). New IT processing technologies such as Hadoop and cloud services enable BA to deal with Big Data to provide descriptive, predictive and prescriptive analysis. BA thus clearly has commonalities with OR (Operational Research). Ranyard, Fildes, and Hu (2015) refer to Business Analytics as "apparently extending the scope of OR practice" (p.1), but the precise relationship between BA and OR remains a matter of debate (e.g. Hindle \& Vidgen, 2017; Liberatore \& Luo, 2010; Mortenson, Doherty, \& Robinson, 2015; Ranyard et al., 2015; Royston, 2013).

Although BA is increasingly being used in organizations, there is a lack of theory linking analytics to innovation, and hence also a lack of practical guidance for managers. In particular, models of the innovation process do not usually include any explicit form of data acquisition, analysis or use. For example, Choi, Narasimhan, and Kim (2016) include only "generating rates" of product and process knowledge, the process of generation being unspecified, and Pan and Li (2016) similarly use only learning rate parameters. An exception is the work of Vidgen, Shaw, and Grant (2017). One of the research questions they considered was "How do organizations extract or create value from [big] data?" (p.627). Their analysis - a Delphi study and three case studies - led to 21 recommendations, though there was no attempt to structure these into a causal model.

Despite strong claims that BA can enhance innovation through product/service differentiation using Big Data (e.g. Stubbs, 2014), there remains a need for theory and empirical evidence to link BA and innovation. Many businesses are still struggling to figure out how, where and when to use Business Analytics to achieve a worthwhile return (Barton \& Court, 2012; Kiron, Prentice, \& Ferguson, 2012; Tambe, 2014). Until the mechanisms underlying BA and its contribution to improved business 
performance are better understood, realizing desired outcomes, such as innovation, remains uncertain. It is notable that the "research agenda for OR in the analytics age" set out by Mortenson et al. (2015) concentrates on research into BA itself rather than on links between BA and outcomes.

Therefore, it is imperative to investigate and confirm if, how and to what extent BA contributes to innovation. This paper seeks to fill this research gap by proposing and validating a new model to explain the relationships between BA and product/service innovation. In so doing, it is important not to regard BA as just a technical development, but also one related to organizational culture. Like any technique, BA will always yield findings of some sort, but only if organizations choose to act on those findings can any innovation occur. Achieving competitive advantage as a result would be clear evidence that organizations have acted on the BA findings.

An appropriate cultural focus when examining BA is the concept of data-driven culture. The term datadriven culture has been in use for many years (e.g. Fitzgerald \& O'Kane, 1999), but with the emergence of Big Data, it has attracted much more attention from practitioners (e.g. Kiron et al., 2012; Kiron \& Shockley, 2011; Lavalle, Lesser, Shockley, Hopkins, \& Kruschwitz, 2011) and researchers (e.g. Dutta \& Bose, 2015; Gillon, Aral, Ching-Yung, Mithas, \& Zozulia, 2014; Holsapple, Lee-Post, \& Pakath, 2014; Li, Thomas, \& Osei-Bryson, 2016; Watson, 2014; Wedel \& Kannan, 2016) because they argue that to maximize the potential BA business value, a relevant organizational culture must be in place. Most OR writers on BA acknowledge the importance of organizational culture, but few consider the acquisition of the data being analyzed, Hindle and Vidgen (2017) and Pape (2016) being notable exceptions. Yet the acquisition of data needs to be a purposeful activity - part of environmental scanning, which is a basic process of any organization to acquire and use data from the external environment to assist management in problem definition and decision making (Aguilar, 1967; Choo, 1999; Lau, Liao, Wong, \& Chiu, 2012; Thayer, 1968). As Big Data technologies enable organizations to acquire a vast array of data about their environments, the role of environmental scanning Big Data must be considered when studying BA's impact on innovation.

To link analytics, data and culture, absorptive capacity theory thus appears highly relevant, because this theory relates to an organization's ability to recognize the value of new, external information, assimilate it and apply it to commercial ends (Cohen \& Levinthal, 1990, page 128). This is a crucial element of the path from BA to innovation. Yet as far as we are aware, ours is the first study to use it to help understand how BA affects innovation, and how managers might change their organizations to reap the benefits from BA.

Therefore, this research aims to examine specifically the relationships between BA, data-driven culture, environmental scanning, new product/service innovation, and competitive advantage. To achieve this 
research aim, this study employs a deductive approach. A number of hypotheses are proposed from an information processing and use perspective, drawing on absorptive capacity theory. These hypotheses are integrated into a research model to explain how BA, working through environmental scanning and datadriven culture, contributes to new product/service innovation, and subsequently competitive advantage. To test the research model, a survey questionnaire is designed to collect quantitative data from UK commercial organizations. Survey data collected from 218 UK companies are used to test the research model.

The remainder of this paper is structured as follows. Section 2 provides a literature review on the key concepts and theoretical considerations. Section 3 discusses the development of the research model. Section 4 explains the research method including research constructs, the associated measurements, and data collection process. Section 5 presents the data analysis and results. It is followed by discussion in section 6 and conclusion in section 7 .

\section{Literature Review and Theoretical Consideration}

This section reviews the definitions of, and theories relevant to, the central concepts of Business Analytics and data-driven culture. It then explains the theoretical considerations to be used to inform the research hypothesis development in section 3. These arise from taking an information processing and use perspective, in order to connect analytics and data/information with innovation and organizational success. The most important element is absorptive capacity theory, which encompasses the third of our central concepts, environmental scanning.

\subsection{Business Analytics (BA)}

The term BA has been widely used in various contexts, but there seems to be no commonly accepted definition of what BA is. Our study follows the Davenport and Harris (2007) definition, which defines BA as "the extensive use of data, statistical and quantitative analysis, explanatory and predictive models, and fact-based management to drive decisions and actions" (p. 7).

While the concept of BA has a long history, as noted by Holsapple et al. (2014), its functions and applications have been re-defined over the years to reflect technological evolution and emerging applications. From the literature, it appears that BA has been classified in a number of ways based on its application domain, evolution process, or key functionality. BA's application domain may include, for example: learning analytics, web analytics, marketing analytics, customer analytics, etc.

A technology evolution perspective is more helpful to explain the recent growth. Chen et al. (2012) argue that Business Intelligence \& Analytics (BI\&A), has evolved from BI\&A 1.0 (Data Base Management System-based structured content), to BI\&A 2.0 (Web-based unstructured content) and BI\&A 3.0 (mobile and sensor based content). Davenport (2013) somewhat similarly suggests that BA has evolved from 
Analytics 1.0, the era of business intelligence, to Analytics 2.0, the era of Big Data, and moving towards Analytics 3.0, the era of data-enriched offerings. Mortenson et al. (2015) promote the term dianoetic management for more broadly data-driven or evidence-based approaches, with business intelligence as the fifth period in its history and BA as the sixth, but this term does not appear to have caught on.

A key functionality perspective gives a still more detailed view. BA can be classified into descriptive, predictive and prescriptive analytics based on a study commissioned by INFORMS (Robinson, Levis, \& Bennett, 2010) and including many different types of analytical tools and techniques. Some of these go back a long way into the history of OR/MS (Management Science): others are based on current leadingedge IT.

Descriptive analytics (DESCBA) uses, for example, business intelligence, data mining, sentiment and affect analysis, web analytics, graph mining, to provide the context and trending information on past or current events, answering what has happened and what is happening.

Predictive analytics (PREDBA) uses, for example, statistical models, machine learning, neural network analysis, and forecasts to provide an accurate projection of future happenings and the reasoning as to why, answering what could happen.

Prescriptive analytics (PRESBA) uses, for example, optimization, simulation, artificial intelligence, casebased reasoning, to recommend one or more courses of action and shows the likely outcome of each decision, providing answers to what the organization should do.

\subsection{Data-driven Culture}

According to Holsapple et al. (2014), a data-oriented culture underscores a pattern of behaviors, practices, and beliefs that are consistent with the principles of analytical decision making. Similarly, Kiron, Ferguson, and Prentice (2013) refer to a data-driven culture as "a pattern of behaviors and practices by a group of people who share a belief that having, understanding and using certain kinds of data and information plays a critical role in the success of their organization" (p. 18). This definition is in line with the mainstream literature on organizational culture, defined as a complex set of values, beliefs, assumptions, and symbols that define the way in which a firm conducts its business (Barney, 1986) and the pattern of shared values, norms, and practices that distinguishes one organization from another (Higgins \& McAllaster, 2002; Schein, 1990). These values and norms define "what is important around here" and "how we do things around here" (Higgins \& McAllaster, 2002, p. 74) and "cultural values are in turn reflected in actual behavioral patterns" (Erdogan, Liden, \& Kraimer, 2006, p. 396).

The concept of data-driven culture, or a similar one, has been recognized by several researchers (e.g. Abbasi, Sarker, \& Chiang, 2016; Dutta \& Bose, 2015; Gillon et al., 2014; Holsapple et al., 2014; Li et al., 2016; Watson, 2014; Wedel \& Kannan, 2016). Davenport, Harris, De Long, and Jacobson (2001) used 
data-oriented or fact-based culture to refer to "data and information were part of the intrinsic value system" that "values data-based decision making" (p. 127), while Davenport (2006) used the "right culture" to mean "a companywide respect for measuring, testing and evaluating quantitative evidence" ( $\mathrm{p}$. 104).

Prior research has emphasized that in order to leverage BA to gain competitive advantage, a company needs to develop a data-driven culture where managerial decisions rely more on data-based insights (Davenport et al., 2001; Kiron et al., 2012; Kiron \& Shockley, 2011; Lavalle et al., 2011). Vidgen et al. (2017) take the need for a data-driven culture for granted. Hindle and Vidgen (2017) present a case study of the Trussell Trust's use of BA that refers to the Trust's intention to become data-driven as a deliberate change in its business model. Becoming data-driven is referred to as "a quest" and "a transformational journey".

\subsection{Using Absorptive Capacity to Theorize the Impact of BA in Innovation}

Researchers argue that information is an important asset helping organizations develop innovation (Cooper, Easingwood, Edgett, Kleinschmidt, \& Storey, 1994; Ottum \& Moore, 1997; Rehm \& Goel, 2015) and gain competitive advantage (Porter \& Millar, 1985). From a marketing perspective, Glazer (1991) argues that organizations need to see beyond the technology and focus on how to manage their information to gain competitive advantage. Examining innovation success from a decision making perspective, Van Riel, Lemmink, and Ouwersloot (2004) point out that information plays an important role in the reduction of managerial uncertainty in high-tech service innovation success.

This research therefore takes the perspective that using BA to help an organization to benefit from Big Data, by turning it into insight and knowledge for innovation, is actually an information processing and use process. This view does not appear to have been taken in the literature until now. Models of paths to innovation success typically do not include data or information; some incorporate knowledge, such as Choi et al. (2016) and Pan and Li (2016), but treat it simply as a property of the organization, with no indication of what might influence or develop it. From this perspective, it is argued that to effectively utilize information for creating competitive advantage, an organization must develop its absorptive capacity (ACAP). Absorptive capacity theory has been used by researchers in their analysis of many complex organizational phenomena including innovation (e.g. Nagati \& Rebolledo, 2012; Najafi Tavani, Sharifi, \& S. Ismail, 2013; Ritala \& Hurmelinna - Laukkanen, 2013). Therefore, we build on absorptive capacity theory to theorize the effect of BA on innovation.

The traditional view of absorptive capacity refers to "a firm's ability to recognize the value of new, external information, assimilate it, and apply it to commercial ends" (Cohen \& Levinthal, 1990, page 128) and emphasizes acquiring and exploiting externally generated knowledge (Zahra \& George, 2002). It is 
argued that information acquisition, assimilation and exploitation are the important organizational routines in developing absorptive capacity (Zahra, Sapienza, \& Davidsson, 2006). Zhang, Zhao, Lyles, and Guo (2015) use similar concepts, but label them knowledge acquisition, assimilation and application. These also closely match the Van Riel et al. (2004) labels of acquisition, diffusion and use. Cuellar and Gallivan (2006) use absorptive capacity as part of a framework for software project risk assessment. They consider absorptive capacity at the organizational level, and combine Zahra and George's four concepts with the socialization element of the SECI knowledge creation model (Nonaka \& Takeuchi, 1995) to give a knowledge transfer process model with five stages - socialization, acquisition, assimilation, transformation and exploitation. The concept of absorptive capacity helps us to focus our attention on how BA applications may influence innovation through acquiring, assimilating and exploiting external information. Data-driven culture can be seen as a part of a process of creating stronger absorptive capacity in the organization by bolstering its assimilation and exploitation elements.

Joshi et al. (2010) have observed that "the application of ACAP in various studies has not been literal, and each study instantiates ACAP and its components to accommodate its unique context" (p. 474). This is also the case for the present study. Although Zahra et al. (2006) and Zahra and George (2002) argue that absorptive capacity can be separated into potential absorptive capacity (acquisition and assimilation) and realized absorptive capacity (exploitation), we feel that it is not possible to separate them in our context. For example, descriptive BA comes under the assimilation activity of potential absorptive capacity, while predictive and prescriptive BA bridge from this into realized absorptive capacity. Environmental scanning can be an acquisition, assimilation and exploitation activity at the same time.

Working with data-driven culture, BA can be a tool to improve environmental scanning. The end result is to bring to market the innovation that is the outcome of the absorptive process, reflecting the effective use and leverage of BA for innovation. The essence of BA is to turn the vast amount of raw data that could be gathered into meaningful and actionable information; therefore, studying the relationship between BA and innovation based on absorptive capacity theory seems to be a plausible direction, but it appears that no such attempt has been reported in the literature.

Scholars from the field of operational research, one of the core disciplines in BA, have partially studied the use of BA applications to acquire, assimilate and exploit external information by both organizations and individual practitioners. For example, O'Brien and Dyson (2007) present and explain a set of operational research tools to support activities such as: setting direction, goals and objectives; assessing both the internal and external environments; generating and assessing strategic ideas before implementing strategic change. More recently, Kunc and O'Brien (2018) performed a survey of the BA literature to identify BA tools that can support similar activities to those described in O'Brien and Dyson (2007). They found that descriptive analytics, e.g. classification algorithms, natural language processing, and predictive 
analytics, e.g. machine learning and Bayesian network algorithms, are employed in assessing the external environments. Most reported BA case studies are, however, typically confined to a single strategic or operational activity, such as the analysis of patient attendance or non-attendance at an outpatient clinic by Harris, May, and Vargas (2016) or that of customer churn by Verbraken, Verbeke, and Baesens (2014). Our study looks at a broader cross-section of an organization's BA activities.

\section{Research Model and Hypotheses}

\subsection{Research Model}

Innovation has many definitions. Whilst there is some overlap between them, there is no agreement (Baregheh et al., 2009). In the context of this research, we use Thompson's simple and straightforward definition that states innovation is "the generation, acceptance and implementation of new ideas, processes, products or services" (1965, p.2). As innovation covers a vast and diversified array of literature, it is necessary to clarify the focus of this study. The central theme of our interest is how companies can gain enhanced insights and intelligence from data using BA and use them to develop new products/services or improve existing ones, and bring them to market. Therefore, the focus of the study is new product/service innovation in an organization.

BA in the era of digitization and Big Data appears to have been hailed as an effective solution for businesses to gain greater insights and intelligence from a variety of data types to uncover hidden patterns, unknown correlations and other useful information. Such information can provide competitive advantage over rival organizations and result in business benefits, such as new product/service innovation. For example, in a recent study, Kiron et al. (2012) claim that "data-savvy organizations are using analytics to innovate and increasingly to gain competitive advantage" (p.1). However, their only empirical evidence is a single question asking respondents if using analytics has created competitive advantage. With the widening availability of data and increasing use of BA, there is a compelling need to establish if, how and to what extent BA contributes to innovation and competitive advantage.

Stubbs (2014) claims that Big Data enables big innovation by enabling competitive differentiation through BA. One way to achieve this is product/service innovation with new insights and knowledge gained through BA. Cooper (1979) states that a product's success originates in two processes: information acquisition and proficiency of the new product development process. Information acquisition is captured in environmental scanning in his study. However, while BA can turn vast amounts of raw data into valuable information, as Droge, Calantone, and Harmancioglu (2008) observe "A huge gap may exist between the amount of information required and the amount of information already possessed by the firm" (p. 227). We follow Droge et al. in regarding environmental scanning (in their terminology, market intelligence) as being a purposeful activity driven by the requirements of the processes that need to use its 
outputs. Even with tools that can handle Big Data, it is neither possible nor desirable simply to acquire information in the hope that one day it may turn out to be useful. Droge et al. also capture the proficiency of the new product development process in their study.

In summary, drawing on prior research and absorptive capacity theory, we thus postulate that BA will enhance a company's innovation through better environmental scanning. Like the Information System Success Model proposed by DeLone and McLean (2003), our research model suggests that first BA is applied and then the use of BA and its information products "impacts and influences the individual user in his or her work, and these individual impacts collectively result in organizational impacts" (DeLone \& McLean, 2003, page 11). For environmental scanning to be purposeful, people in the organization need to realize and understand that purpose.

The consideration of a firm's absorptive capacity determines the most relevant areas in the research model for the present study to examine. These areas are BA as an essential part of absorptive capacity improving environmental scanning and strengthening data-driven culture, environmental scanning bridging BA and innovation performance as the outcome, and data-driven culture mediating the effect of BA on environmental scanning activities and moderating the paths between environmental scanning and innovation performance (see discussion in section 4). The resultant research model is shown in Figure 1. In the next sub-section, a number of hypotheses are developed to be tested with the empirical data. 


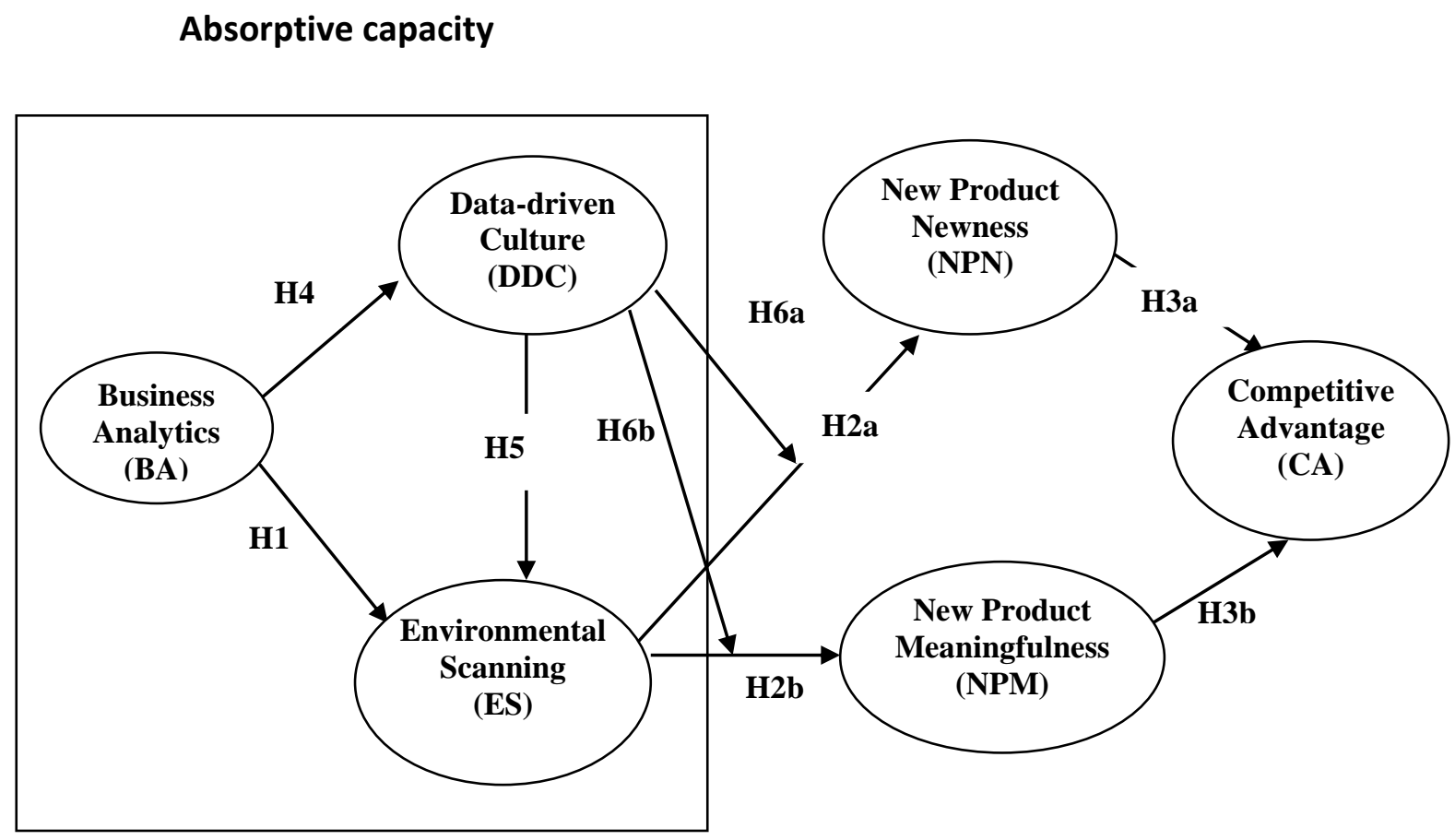

Figure 1. Research model and hypotheses

\subsection{Hypothesis Development}

The first hypothesis follows from the arguments in the previous sub-section. We propose:

H1 - BA has a positive effect on Environmental Scanning.

\subsubsection{BA, Environmental Scanning and New Product Newness and Meaningfulness.}

Dahlander and Gann (2010) reiterate that innovation is not an isolated activity; it involves engagement and interaction with others both internal and external to the firm to acquire the necessary ideas and resources. Environmental scanning, as an important element of absorptive capacity, is a basic process of any organization to acquire data from the external environment to be used in problem definition and decision making (Thayer, 1968). The primary purpose of environmental scanning is to provide a comprehensive view and understanding of the current and future condition of the environment that can be used as a foundation for guiding product/service development (Maier, Rainer Jr, \& Snyder, 1997). Successful organizations understand their environment and provide products and services that reflect - or even anticipate - changes within it. The concept of environmental scanning has been used in research on organizational strategy and strategic decision making (e.g. Bourgeois, 1980; Hambrick, 1982), but its direct relationship to innovation has not been well explored. 
In the context of innovation, environmental scanning refers to a firm's activities to gather information about its environment as a foundation for developing better understanding for innovation (Miller \& Friesen, 1982). Keller and Holland (1975) and Tushman (1977) argue that a primary limitation on a firm's innovativeness is its ability to recognize the needs and demands of its external environment through environmental scanning. However, most innovation studies concerning environmental scanning are in the area of market orientation. The relationship between market orientation and innovation, particularly product newness, has been debated for decades (Atuahene-Gima, 1996). Research on market orientation mostly concerns if market orientation as a business strategy or organizational culture could contribute to better product innovation (e.g. Hurley \& Hult, 1998). The results so far are inconclusive: some suggest a negative impact (e.g. Atuahene-Gima, 1996; Hong, Song, \& Yoo, 2013), while others demonstrate otherwise (e.g. Augusto \& Coelho, 2009). Liberatore and Luo (2010) observe that "organizations involved in analytics today seem to subscribe to the market-driven concept" (p.317), the date of their study meaning they were referring to the early adopters of BA, although this was not a formal finding of their research.

It is argued that although findings about market orientation and innovation provide useful background understanding, they are not directly applicable in the context of BA applications because the focus of our concern is not a firm's business strategy, but its absorptive capacity reflected in purposefully acquiring external information through environmental scanning activity, to be assimilated and exploited. It appears that there has been very limited research on linking environmental scanning to product/service innovation as opposed to a strategic focus.

Turning to innovation performance, Stock and Zacharias (2013) conduct an extensive literature review regarding the dimensions of new product/service innovation. They find newness and meaningfulness have each been widely used, often as part of a two-dimensional conception of innovativeness, and that the inclusion of meaningfulness enables a more detailed understanding of the innovation phenomenon at program level than newness alone. Newness refers to the inherent novelty or originality of the product/service, while meaningfulness comprises the usefulness, value and appropriateness to the customer (Stock \& Zacharias, 2013). We follow the examples of Sethi and Sethi (2009) and Stock and Zacharias (2013) in their innovation studies and adopt the dimensions of new product/service newness (or novelty), and meaningfulness for the present study. To save space, the term "new product" in the rest of the paper should be understood as covering both new products and new services.

As discussed, it is assumed in this research that BA applications are the driver for more and different ways of environmental scanning. This then enables the firm to focus on the use of BA to generate relevant insight into a firm's changing environment, especially the needs for innovation, perhaps due to changing customers' desires, buying patterns or new developments of competitors. Nevertheless, in any individual 
instance, the usefulness and relevance of the specific information from the environmental scanning will influence new product development: "garbage in, garbage out" is as true as ever. Therefore, we propose:

H2a - Environmental Scanning has a positive effect on New Product Newness.

$\boldsymbol{H} \mathbf{2 b}$ - Environmental Scanning has a positive effect on New Product Meaningfulness.

While this completes the paths to action in the form of new product development, the model needs to go further to include successful action, not just innovation for its own sake. The majority of innovation studies use competitive advantage as the measure of success (e.g. Chen, Lin, \& Chang, 2009; Herrera, 2015; Im \& Workman Jr, 2004; Lengnick-Hall, 1992), with just a few exceptions such as Chen and Hung (2014) who use innovation performance, and Stock and Zacharias (2013) who use customer loyalty. Indeed, Sumo, van der Valk, Bode, and van Weele (2016) recently observe "Radical and incremental innovation in products and services is critical for firms' sustained competitive advantage" (p. 1482). We therefore side with the majority and propose:

H3a - New Product Newness has a positive effect on Competitive Advantage.

H3b - New Product Meaningfulness has a positive effect on Competitive Advantage.

\subsubsection{BA, Data-Driven Culture and Environmental Scanning.}

The role of organizational culture in innovation has been well studied and discussed (Büschgens, Bausch, $\&$ Balkin, 2013). Given our information processing and use perspective, we focus on one particular aspect of organizational culture, which is data-driven culture as defined in section 2.2.

Because this study aims to understand BA's impact rather than its antecedents, we argue that the use of BA enhances data-driven culture in an organization. In their survey and interviews on BA applications, Kiron et al. (2013) find that BA can make an organization more data-driven because of the availability of analytics. Managers who were interviewed in their case studies explain that with the availability of BA, "we've become much more data driven and analytics oriented" (Director of a utility company) and "everything that we do is driven by analytics" (CEO of an online dating service) (Kiron et al., 2013, p. 7). Kiron et al. (2012) reveal that companies that are successful in BA applications are not just seeing analytics as an important path to value; instead, they are evolving and changing as organizations as a result of their experience with analytics. Therefore, we posit:

H4-BA has a positive effect on Data-Driven Culture.

Evidence from Kiron et al. (2012) also suggests that having a culture that has evolved based more on data, has caused the organizations to change their behavior. In relation to our focus on absorptive capacity and innovation, the most relevant area of change is environmental scanning. Bearing in mind the conception of environmental scanning as a purposeful activity driven by the downstream processes, it is also argued 
that data-driven culture affects environmental scanning that, in turn, helps innovation. Therefore, we propose:

\section{H5 - Data-Driven Culture has a positive effect on Environmental Scanning.}

It can be argued that more use of BA is not likely to mean better environmental scanning unless there is a widespread data-driven culture that says environmental scanning is important and therefore gets it right. Otherwise, although the acquisition part of absorptive capacity is better, the assimilation and exploitation may not be, because no-one really cares about the data coming out of environmental scanning. Therefore, it is plausible that data-driven culture can mediate the relationship between BA and environmental scanning. Examining this mediation relationship can provide a richer understanding on how the three important constructs of absorptive capacity, i.e. BA, environmental scanning and data-driven culture, work together to impact on innovation.

\subsubsection{Data-driven Culture and New Product Newness and Meaningfulness.}

Research on absorptive capacity and its impact on organizational performance has suggested that organizational factors such as culture can moderate the path between absorptive capacity and outcomes (e.g. Leal-Rodríguez, Ariza-Montes, Roldán, \& Leal-Millán, 2014; Zahra \& George, 2002). Also, a number of studies (Evanschitzky, Eisend, Calantone, \& Jiang, 2012; Mohr, Young, \& Burgess, 2012) have demonstrated that organizational culture can moderate the path between organizational factors and organizational performance. For example, Evanschitzky et al. (2012) conduct a meta-analysis on success factors of product innovation and the findings of their analysis identify and emphasize the moderating effect of culture. Similarly, it is argued in this study that the relationship between absorptive capacity as an organizational factor in this context and new product newness and meaningfulness as organizational performance indicators can be moderated by data-driven culture. A stronger data-driven culture will encourage an organization to value data and use insights gained from environmental scanning to improve new product newness and meaningfulness, thus to gain better competitive advantage. One important finding by Kiron et al. (2012) is that "a data-oriented culture makes it easier for organizations to innovate when decision makers have confidence in where the data comes from, how it is developed and by whom" (p. 10). Therefore, based on the analysis of existing literature in absorptive capacity, innovation, and culture, we propose:

H6a - Data-Driven Culture positively moderates the relationship between Environmental Scanning and New Product Newness.

H6b - Data-Driven Culture positively moderates the relationship between Environmental Scanning and New Product Meaningfulness. 


\section{Research Method}

The research model and its associated hypotheses are tested through a questionnaire survey. Data are collected from an online questionnaire survey with UK companies.

\subsection{Model Constructs and Measurement}

\section{Business Analytics (BA)}

As examined in section 2, although BA has existed for several decades, it has two important additional features in the era of Big Data. Firstly, BA has to deal with large volumes, unstructured and constantly changing data, going far beyond the complexity of traditional database work; and secondly, BA applications encompass various newer types of analytics techniques, such as: text and web analytics, graph mining, sentiment and affect analysis, and social network analytics. As this is a new research area and there are few empirically validated measurement items, we have developed new constructs and measures for BA, drawing on BA literature (Delen \& Demirkan, 2013; Kiron et al., 2012; Lavalle et al., 2011). The level of BA applications is measured by the use of descriptive, predictive and prescriptive analytics (DESCBA, PREDBA and PRESBA) respectively (Robinson et al., 2010).

\section{Innovation Performance}

Innovation performance is a multi-dimensional concept and no single innovation measurement is able to capture its complex nature. For example, innovation performance has been measured through perceived performance against competitors (Subramaniam \& Youndt, 2005) or objective measures such as the number of patents developed (e.g. Ahuja, 2000; Stuart, 2000).

Innovation related constructs together with their measurements are adapted from the relevant innovation literature to the current research context, using indicators which have already been empirically validated by prior studies. Stock and Zacharias (2013) conduct an extensive literature review regarding the dimensions of new product innovation. They find both product newness and meaningfulness have each been widely used, often as part of a two-dimensional conception of innovativeness. Those for new product newness (NPN) are from Miller and Friesen (1982), Frishammar and Åke Hörte (2005) and Droge et al. (2008); and those for new product meaningfulness (NPM) from Im and Workman Jr (2004) and Kim, Im, and Slater (2013).

\section{Data-Driven Culture (DDC)}

Based on Davenport et al. (2001), Kiron and Shockley (2011), Kiron et al. (2012) and Lavalle et al. (2011) data-driven culture is reflected in our study by measuring organizational belief (DDCBELI), attitude (DDCOPEN) and behavior towards using insight (DDCDEP, DDCUSE) and information generated from data (DDCNEED). 


\section{Environmental Scanning (ES)}

The measures for environmental scanning are directly adopted from Miller and Friesen (1982) that describe how a firm gathers information about its environment in relation to its clients, competitors, customers, technology and markets.

\section{Competitive Advantage (CA)}

Based on Im and Workman Jr (2004), Kiron et al. (2012), Lavalle et al. (2011), and Kiron and Shockley (2011a), we measure competitive advantage in terms of the manager's perception of whether his/her organization has been more profitable (CAPRO), increased its sales (CASAL) and its market share (CAMAR) faster, and had a better return on investment (CAROI) than its key competitors. These subjective measurements have been commonly used by prior studies (e.g. Armstrong \& Sambamurthy, 1999; Kearns \& Sabherwal, 2007).

The constructs and their indicators are summarized in Table 1.

Table 1. Constructs and indicators of the study.

\begin{tabular}{|c|c|c|}
\hline Constructs & Indicators & References \\
\hline $\begin{array}{l}\text { Business } \\
\text { Analytics (BA) } \\
\text { (Formative) }\end{array}$ & $\begin{array}{l}\text { Please indicate the extent to which your company uses the following types of } \\
\text { Business Analytics on a 7-point scale.( } 1 \text { - none at all, } 7 \text { - extensively) } \\
\text { - DESCBA: Descriptive (What has happened and what is happening?): e.g. } \\
\text { uses business intelligence and data mining to provide the context of and } \\
\text { trending information on past or current events. } \\
\text { - PREDBA: Predictive analytics (What could happen?): e.g. uses statistical } \\
\text { models and forecasts to provide an accurate projection of the future } \\
\text { happenings and the reasoning as to why. } \\
\text { - PRESBA: Prescriptive analytics (What should we do?): e.g. uses optimisation } \\
\text { and simulation to recommend one or more courses of action and show the } \\
\text { likely outcome of each decision. }\end{array}$ & $\begin{array}{l}\text { (Delen } \quad \& \\
\text { Demirkan, 2013; } \\
\text { Kiron et al., 2012; } \\
\text { Robinson et al., } \\
2010 \text { ) }\end{array}$ \\
\hline $\begin{array}{l}\text { Data-driven } \\
\text { Culture (DDC) } \\
\text { (Formative ) }\end{array}$ & $\begin{array}{l}\text { To what extent do you agree or disagree with the following statements about } \\
\text { you company's culture ( } 1 \text { - strongly disagree, } 7 \text { - strongly agree). } \\
\text { - DDCBELI: We believe that having, understanding and using data and } \\
\text { information plays a critical role } \\
\text { - DDCOPEN: We are open to new ideas and approaches that challenge current } \\
\text { practices on the basis of new information } \\
\text { - DDCDEP: We depend on data-based insights to support decision making } \\
\text { - DDCUSE: We use data-based insights for the creation of new services or } \\
\text { products } \\
\text { - DDCNEED: Individuals have need for data to make decisions }\end{array}$ & $\begin{array}{l}\text { (Davenport et al., } \\
\text { 2001; Kiron et al., } \\
\text { 2012; Kiron \& } \\
\text { Shockley, 2011; } \\
\text { Lavalle et al., } \\
\text { 2011) }\end{array}$ \\
\hline $\begin{array}{l}\text { Environmental } \\
\text { Scanning (ES) } \\
\text { (Formative) }\end{array}$ & $\begin{array}{l}\text { To what extent do you agree or disagree with the following statements about the } \\
\text { following activities that had been undertaken to gather information about your } \\
\text { company's environment in the past five years }(1-\text { strongly disagree, } 7 \text { - } \\
\text { strongly agree). } \\
\text { - ESROU: Routine gathering of opinions from clients } \\
\text { - ESSPE: Special market research studies } \\
\text { - ESCOM: Explicit tracking of the policies and tactics of competitors } \\
\text { - ESFOR: Forecasting sales, customer preferences, technology, etc. }\end{array}$ & $\begin{array}{l}\text { Miller \& Friesen, } \\
1982\end{array}$ \\
\hline $\begin{array}{l}\text { New } \\
\text { Product/Service }\end{array}$ & $\begin{array}{l}\text { Rate your company's product/service innovation in the past five years } \\
\text { From } 1 \text { to } 7 \text { : }\end{array}$ & $\begin{array}{l}\text { (Droge et al., } \\
\text { 2008; Frishammar }\end{array}$ \\
\hline
\end{tabular}




\begin{tabular}{|c|c|c|}
\hline $\begin{array}{l}\text { Newness (NPN) } \\
\text { (Formative) }\end{array}$ & $\begin{array}{l}\text { NPNRD: 1-There had been a strong emphasis on the marketing of true and tried } \\
\text { products/services --- 7- There had been a strong emphasis on R\&D, } \\
\text { technological leadership, and innovation } \\
\text { NPNDRA: } 1 \text { - Changes in products/services had been mostly of a minor nature - } \\
\text {--- 7-Changes in products/services had been mostly dramatic } \\
\text { NPNMAN: } 1 \text { - We had marketed no new lines of products/services ---- 7- We } \\
\text { had marketed many new lines of products/services }\end{array}$ & $\begin{array}{l}\text { \& Åe Hörte, } \\
\text { 2005; Miller \& } \\
\text { Friesen, 1982) }\end{array}$ \\
\hline $\begin{array}{l}\text { New } \\
\text { Product/Service } \\
\text { Meaningfulness } \\
\text { (NPM) } \\
\text { (Reflective) }\end{array}$ & $\begin{array}{l}\text { Compared with those of our key competitors in the past five years, the new } \\
\text { products or services we offered were ( } 1 \text { - strongly disagree, } 7 \text { - strongly agree). } \\
\text { - NPMREL: relevant to customers' needs and expectations } \\
\text { - NPMSUI: considered suitable for customers' desires } \\
\text { - NPMAPP: appropriate for customers' needs and expectations } \\
\text { - NPMUSE: useful for customers }\end{array}$ & $\begin{array}{l}\text { (Im \& Workman } \\
\text { Jr, 2004; Kim et } \\
\text { al., 2013) }\end{array}$ \\
\hline $\begin{array}{l}\text { Competitive } \\
\text { Advantage } \\
\text { (CA) } \\
\text { (Reflective) }\end{array}$ & $\begin{array}{l}\text { To what extent you agree or disagree with the following statements about your } \\
\text { company's performance, on average, in the past five years }(1-\text { strongly } \\
\text { disagree, } 7 \text { - strongly agree). } \\
\text { - CAPRO: We are more profitable than our key competitors } \\
\text { - CASAL: Our sales increased faster than our key competitors } \\
\text { - CAMAR: Our market share increased faster than our key competitors } \\
\text { - CAROI: We had better return on investment than our key competitors }\end{array}$ & $\begin{array}{l}\text { (Im \& Workman } \\
\text { Jr, 2004) }\end{array}$ \\
\hline
\end{tabular}

\subsection{Data Collection and Sample Size}

We collected data from both medium (number of employees between 50 and 249 inclusive) and large (250 or more employees) UK enterprises as they are expected to have the "capabilities" and "substantial resources" to employ various types of BA for business improvement (Gillon et al., 2014). We generated a questionnaire survey using a seven-point Likert scale (ranging from 1 - strongly disagree to 7 - strongly agree, except where shown otherwise in Table 1) to capture the responses to the measurements of all constructs. The questionnaire contained five sections covering 1. respondent and company profile, 2 . use of BA, 3. data-driven culture and environmental scanning, 4. new product innovation, 5. perceived competitive advantage. Table 1 shows the questions used in the survey to measure the research constructs. The survey instruments were developed based on the literature review and definitions discussed above and were then scrutinized by subject experts. After a few revisions, the survey was tested with four academic and business experts to ensure that the respondents understood the questions and there were no problems with the wording or measurements, which resulted in a few minor formatting and presentation modifications. The survey questionnaire was then distributed to managers electronically through Qualtrics, which is a world leading well-developed online survey tool. The target population was the senior managers in the firm and their email addresses were identified from the FAME (Financial Analysis Made Easy) database. FAME provides financial information on almost 10 million public and private UK \& Irish companies that is updated daily. They were also reminded to pass the survey to another person if they believed that he/she was in a better position to answer the survey questions. Four rounds, one week apart, of emails including a cover letter with the questionnaire survey were sent. Each respondent was offered a 
summary of the results and the opportunity to enter into a draw to win one of five Amazon gift certificates (£100 each).

Using Qualtrics software, a total of 102,237 survey invitations were sent by email. However, the majority of them were never opened. Of all sent emails, 578 surveys were opened; of these, we received 232 responses and 218 were usable responses. Unfortunately, with the software used for distributing the survey invitation, there was no means to know if the email actually was delivered to the intended recipient's inbox. As a result, calculating a true response rate appears impossible because the apparent response rate of $0.21 \%$ would seriously under-represent the true rate, whereas a response rate based on the number of opened surveys and completed surveys, which is $37.7 \%$, would similarly over-represent the true rate. The literature does not seem to have come up with agreed methods or expected rates for conducting surveys with mass emails such as ours. For example, Kianto, Andreeva, and Pavlov (2013), using different mailing software, report a survey where, of 10,000 emails sent, only 4,064 reached the individual's inbox.

We therefore instead consider the number of responses from the perspective of building an adequate model. In the structural model, the maximum number of arrows pointing at a construct is two. In order to detect a minimum $\mathrm{R}^{2}$ value of 0.10 in any of the constructs at a significance level of $1 \%$, the minimum sample size required is 158 (Hair, Hult, Ringle, \& Sarstedt, 2014). Since we had 218 usable responses, this minimum sample size requirement is thus met.

\section{Data Analysis and Results}

The hypotheses were tested empirically using partial least squares structural equation modeling (PLSSEM) based on survey data. PLS-SEM is recommended to be well-suited for research situations where theory is less developed and formative constructs are part of the structural model, as here (Hair, Ringle, \& Sarstedt, 2013).

\subsection{Data Screening}

Data screening was performed using SPSS21 in two stages. Initially, observations where the missing data exceeded 10\% were removed (Hair, Black, Babin, \& Anderson, 2010), thus reducing the 232 responses we received to 225 . The remaining data set still had missing values but fewer than $5 \%$ on a single variable, which may be of little concern (Amabile, 1983) if the values are missing completely at random (MCAR). To check if the remaining missing data were MCAR, Little's MCAR test (Little, 1988) was then conducted and was found to be significant. Such observations were therefore completely removed, leaving a total of 218 responses to be used in the analysis.

\subsection{Respondents' Profile}


Table $2 \mathrm{a}$ and $2 \mathrm{~b}$ summarize the company profile and the respondent profile in terms of their organizational positions and years of experience in their current firms and industry. As indicated, we used a key informant approach based on position in the organization (Bagozzi, Youjae, \& Phillips, 1991) to collect data. The reported positions of the respondents suggested that $20 \%$ of the respondents were in a senior managerial position and the rest of them were in a middle managerial position, thus the respondents were considered to be able to address the survey questions.

Table 2a. Company profile

\begin{tabular}{|c|c|c|c|}
\hline \multicolumn{5}{|c|}{ Company profiles (n=218) } \\
\hline Industry & $\%$ & Number of employees & $\%$ \\
\hline Manufacturing & 30 & $50-249$ & 62 \\
\hline Prof Services & 15 & $250-4999$ & 26 \\
\hline Technology & 9 & $>=5000$ & 12 \\
\hline Retail/Wholesale & 8 & & \\
\hline Fin Services & 5 & & \\
\hline Other & 33 & & \\
\hline
\end{tabular}

Table $2 b$. Respondent profile

\begin{tabular}{|c|c|c|c|c|}
\hline \multicolumn{5}{|c|}{ Respondent profiles (n=218) } \\
\hline Positions & $\%$ & $\begin{array}{c}\text { Years of } \\
\text { experience (x) }\end{array}$ & $\begin{array}{c}\text { in the } \\
\text { firm \% }\end{array}$ & $\begin{array}{c}\text { in the } \\
\text { industry } \%\end{array}$ \\
\hline CEO/MD/Partner & 20 & $\mathrm{x} \leq 5$ & 13 & 2 \\
\hline Operations director & 16 & $5<\mathrm{x} \leq 10$ & 31 & 10 \\
\hline Fin/Acc director & 12 & $10<\mathrm{x} \leq 15$ & 18 & 9 \\
\hline Mktg/Sales director & 8 & $15<\mathrm{x} \leq 20$ & 13 & 15 \\
\hline CIO/IT Manager & 7 & $20<\mathrm{x} \leq 25$ & 11 & 13 \\
\hline Other directors & 37 & $\mathrm{x}>25$ & 14 & 51 \\
\hline
\end{tabular}

\subsection{Common Method and Non-respondent Bias}

This research used both procedural and statistical remedies to control for common method bias (Podsakoff, MacKenzie, \& Podsakoff, 2012). The procedural remedy used was to improve scale items, especially unfamiliar items, through defining them clearly and keeping the questions simple and specific thereby to eliminate ambiguity. In addition, rather than just labeling the end points, every point on the response scale was labeled, which also helps reduce item ambiguity (Krosnick, 1999). Additionally, Harman's single-factor test was conducted as a statistical remedy to assess common method bias that may affect the true correlations between variables and cause biased parameter estimates (Malhotra, Patil, \& Kim, 2007). The test result indicated that the first factor accounted for $35.90 \%$ of the total variance; thus, there is no evidence of a substantial common method bias in this study.

Potential bias from non-response or self-selection concern was assessed by conducting two tests. The first test compared respondents in the first two rounds $(n=122)$ with later respondents $(n=96)$ on all measures 
through a t-test. The t-test results did not find a significant difference at a significance level of 5\% (twotailed) between the two respondent groups, suggesting an absence of non-response bias (Armstrong \& Overton, 1977). The second test compares the distribution of the company size of the respondents with that of the complete sampling frame, based on the known value for the population approach (Armstrong \& Overton, 1977). A nonparametric chi-square test comparing the distribution of the observed and expected values found no significant difference at the $5 \%$ level.

\subsection{Evaluation of the Measurement Model}

Since the model contains both reflective and formative constructs, a separate set of analyses was conducted following the recommendations made by Hair et al. (2014). The reflective measurement model was evaluated by considering internal consistency (composite reliability), indicator reliability, convergent validity and discriminant validity.

The composite reliability (CR) scores summarized in Table 3 indicated that results based on these constructs should be consistent, since all constructs met the recommended threshold value for acceptable reliability, that is, both CR and Cronbach's $\alpha$ should be larger than 0.70 .

Indicator reliability was assessed by observing the factor loadings and each indicator's variance; the former should be larger than 0.70 and the latter should be no less than 0.50 . As summarized in Table 3 , indicator reliability was satisfactory. Convergent validity was also satisfactory since the average variance extracted (AVE) value for each construct was no less than the recommended threshold value of 0.50 .

Table 3. Convergent validity and internal consistency reliability

\begin{tabular}{|c|c|c|c|c|c|c|}
\hline \multicolumn{7}{|c|}{ Convergent Validity and Internal Consistency Reliability } \\
\hline Construct & Indicator & Loading & $\begin{array}{l}\text { Indicator } \\
\text { Reliability }\end{array}$ & $\begin{array}{l}\text { Composite } \\
\text { Reliability }\end{array}$ & $\begin{array}{l}\text { Cronbach's } \\
\text { Alpha }\end{array}$ & AVE \\
\hline \multirow{4}{*}{ NPM } & NPMAPP & 0.93 & 0.86 & \multirow{4}{*}{0.95} & \multirow{4}{*}{0.93} & \multirow{4}{*}{0.84} \\
\hline & NPMREL & 0.92 & 0.85 & & & \\
\hline & NPMSUI & 0.90 & 0.81 & & & \\
\hline & NPMUSE & 0.91 & 0.83 & & & \\
\hline \multirow{4}{*}{$\mathrm{CA}$} & CAMAR & 0.91 & 0.83 & \multirow{4}{*}{0.92} & \multirow{4}{*}{0.89} & \multirow{4}{*}{0.75} \\
\hline & CAPRO & 0.80 & 0.64 & & & \\
\hline & CAROI & 0.84 & 0.71 & & & \\
\hline & CASAL & 0.92 & 0.85 & & & \\
\hline
\end{tabular}

Discriminant validity was assessed via two tests. The first was to analyze the Fornell-Larcker criterion (Hair et al., 2013) to evaluate if the square root of the AVE value for each construct was greater than the correlation of that construct with any other construct, which was true. The second test was to observe if 
each reflective indicator loaded highest on the construct it was associated with, which was also true, thus demonstrating discriminant validity was satisfactory. The analysis results are summarized in table 4 .

Table 4. Means, standard deviation, and correlations

\begin{tabular}{|ll|l|l|l|l|l|l|l|l|}
\hline & & Mean & S.D. & 1 & 2 & 3 & 4 & 5 & 6 \\
\hline 1. & BA & 4.032 & 1.531 & n/a & & & & & \\
\hline 2. & CA & 4.737 & 1.183 & $0.205^{* *}$ & $\mathbf{0 . 8 6 9}$ & & & & \\
\hline 3. & DDC & 4.951 & 1.257 & $0.611^{* *}$ & $0.232^{* *}$ & n/a & & & \\
\hline 4. & ES & 4.424 & 1.253 & $0.493^{* *}$ & $0.276^{* *}$ & $0.619^{* *}$ & n/a & & \\
\hline 5. & NPM & 5.710 & 0.817 & 0.037 & $0.395^{* *}$ & $0.163^{*}$ & $0.274^{* *}$ & $\mathbf{0 . 9 1 3}$ & \\
\hline 6. & NPN & 4.288 & 1.264 & $0.324^{* *}$ & $0.347^{* *}$ & $0.430^{* *}$ & $0.462^{* *}$ & $0.297^{* *}$ & n/a \\
\hline
\end{tabular}

Square root of AVE on the diagonal; n/a -not applicable to formative constructs ${ }^{*} \mathrm{p}<0.01,{ }^{*} \mathrm{p}<0.05$

The formative measurement model was validated in terms of assessing multicollinearity, the indicator weights, significance of the weights, and the indicator loadings (Hair et al., 2014). To assess the level of multicollinearity, the values of variance inflation factor (VIF) of all formative constructs were evaluated. The threshold value suggested for VIF is 3.3 (Petter, Straub, \& Rai, 2007) or 5 (Hair et al., 2014). All VIF values associated with BA and DDC indicators were below 3.3, thus there were no major multicollinearity issues. All but five indicators' outer weights were significant, indicating each formative indicator captured a portion of the associated construct's scope. These outer weights indicated that the associated formative indicators were meaningful and satisfactorily contributed to forming their associated constructs. Therefore, based on the above evaluations, the formative part of the measurement model was valid.

\subsection{Evaluation of the Structural Model and Hypothesis Testing}

Smart PLS 2.0 M3 was used for testing the hypotheses and assessing the predictive power of the research model. A bootstrapping procedure (5,000 samples) was used to assess the significance of the hypothesized paths and the amount of variance in the dependent variables attributed to the explanatory variables (Hair et al., 2014).

Control variable analysis. To understand whether firm size, industry type, respondent job title and years of job experience have an effect on competitive advantage through innovation, this study controlled for these factors by the use of dummy variables. The results indicated that none of them had a statistically significant effect (at the 5\% level) on competitive advantage (see Figure 2).

Hypothesis Testing. The results of hypothesis testing are presented in Figure 2 and Table 5. While H1 to H5 and H6b were supported, H6a was rejected. 


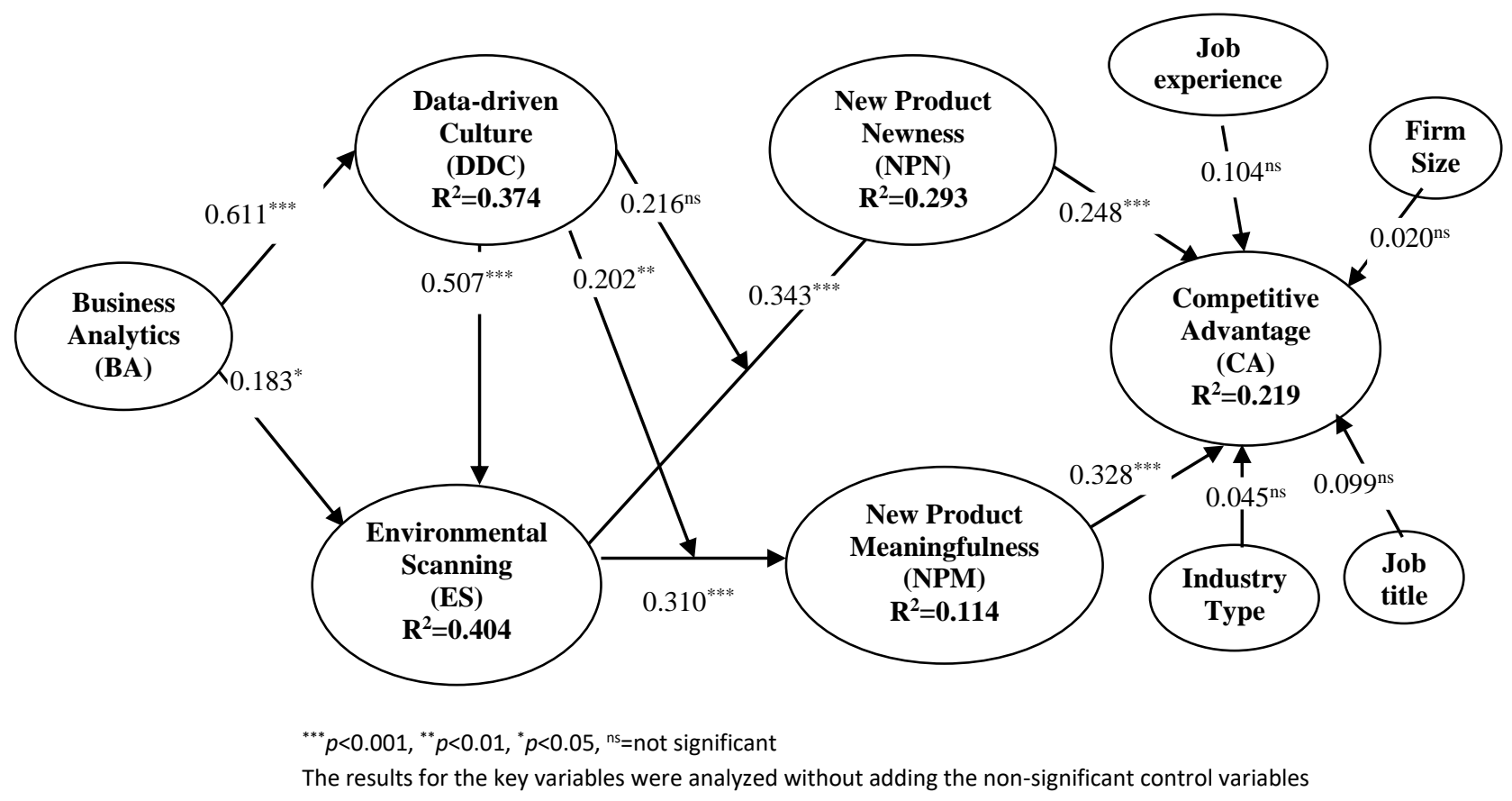

Figure 2. Research hypotheses test results

Table 5. Summary results of hypothesis testing

\begin{tabular}{|l|l|l|l|l|l|}
\hline & $\begin{array}{l}\text { Hypothesized } \\
\text { Path }\end{array}$ & $\begin{array}{l}\text { Standard path } \\
\text { coefficient }\end{array}$ & $\begin{array}{l}\text { Standard } \\
\text { error }\end{array}$ & $p$-Values & $\begin{array}{l}\text { Empirical } \\
\text { evidence }\end{array}$ \\
\hline Hypothesis 1 & BA->ES & 0.183 & 0.0788 & $0.0241^{* *}$ & Supported \\
\hline Hypothesis 2a & ES->NPN & 0.343 & 0.0824 & $0.0001^{* * *}$ & Supported \\
\hline Hypothesis 2b & ES->NPM & 0.310 & 0.0869 & $0.0003^{* * * *}$ & Supported \\
\hline Hypothesis 3a & NPN->CA & 0.248 & 0.0645 & $0.0001^{* * *}$ & Supported \\
\hline Hypothesis 3b & NPM->CA & 0.328 & 0.0577 & $0.0000^{* * *}$ & Supported \\
\hline Hypothesis 4 & BA->DDC & 0.611 & 0.0518 & $0.0000^{* * *}$ & Supported \\
\hline Hypothesis 5 & DDC->ES & 0.506 & 0.0704 & $0.0000^{* * *}$ & Supported \\
\hline Hypothesis 6a & ES*DDC->NPN & 0.216 & 0.1127 & $0.0583^{\text {ns }}$ & Rejected \\
\hline Hypothesis 6b & ES*DDC->NPM & 0.202 & 0.0739 & $0.0047^{* *}$ & Supported \\
\hline
\end{tabular}

More specifically, to evaluate H6a and H6b, that is, the moderating effect of DDC (data-driven culture) on the relationships between ES and NPN and between ES and NPM respectively, the function of "Create Moderating Effect" provided by Smart PLS 2.0 M3 was used, with ES as a predictor variable and DDC as a moderator variable. The bootstrapping result indicated that DDC has no statistically significant moderating effect on the relationship between ES and NPN but it does have a statistically significant moderating effect of 0.202 ( $\mathrm{p}<0.01)$ on the relationship between ES and NPM. Thus, H6a is rejected, H6b is supported. 
The mediating role of DDC on the relationship between BA and ES was evaluated following the process recommended by Baron and Kenny (1986). The results are summarized in Table 6. The relative size of the mediating effect was decided by calculating the variance accounted for (VAF) based on Shrout and Bolger (2002), who recommend that $\mathrm{VAF}>0.80$ means full mediation, $0.20 \leq \mathrm{VAF} \leq 0.80$ partial mediation, and $\mathrm{VAF}<0.20$ no mediation. The VAF value of 0.37 suggested that DDC partially mediates the effect of BA on ES.

Table 6. The mediating effect of DDC on the relationship between BA and ES

\begin{tabular}{|l|l|l|l|l|l|}
\hline Hypothesis & $\begin{array}{l}\text { Direct effect } \\
\text { without } \\
\text { mediation }\end{array}$ & $\begin{array}{l}\text { Direct effect } \\
\text { with } \\
\text { mediation }\end{array}$ & $\begin{array}{l}\text { Indirect } \\
\text { effect }\end{array}$ & VAF & $\begin{array}{l}\text { Mediation type } \\
\text { observed }\end{array}$ \\
\hline Based on Hypotheses 4 and 5 & $0.502^{* * *}$ & $0.183^{*}$ & $0.310^{* * *}$ & 0.37 & Partial \\
\hline
\end{tabular}

\section{Discussion}

\subsection{Key findings and research contributions}

The empirical evidence has provided strong support for the proposed model. As shown in Figure 2, all of the research hypotheses are supported, except for the moderating effect of data-driven culture on the relationship between environmental scanning and new product newness (H6a). The key findings suggest that a firm's absorptive capacity concerning BA, environmental scanning and data-driven culture in the present study directly improves a firm's innovation in terms of new product newness and meaningfulness. The findings demonstrate that BA affects environmental scanning (H1: path coefficient $=0.183$ at $\mathrm{p}<0.05$ ) which in turn helps to enhance a company's innovation in terms of new product newness (H2a: path coefficient $=0.343$ at $\mathrm{p}<0.001)$ and meaningfulness $(\mathrm{H} 2 \mathrm{~b}$ : path coefficient $=0.310$ at $\mathrm{p}<0.001)$, the latter results being consistent with research on the effects of environmental scanning going all the way back to Miller and Friesen (1982), but not in agreement with the results of Frishammar and Åke Hörte (2005). BA positively and strongly influences data-driven culture with a very high path coefficient (H4: path coefficient $=0.611$ at $\mathrm{p}<0.001$ ), and data-driven culture positively and strongly influences environmental scanning (H5: path coefficient=0.506 at $\mathrm{p}<0.001$ ). Based on $\mathrm{H} 4$ and $\mathrm{H} 5$, the findings also demonstrate that the effect of BA's contribution is mediated through data-driven culture in the organization; this is consistent with the effect of organizational culture more broadly as found by other researchers (Wyld \& Maurin, 2009) although their focus is not data-driven culture per se. New product newness (H3a: path coefficient $=0.248$ at $\mathrm{p}<0.001)$ and new product meaningfulness (H3b: path coefficient $=0.328$ at $\mathrm{p}<0.001)$ both enhance competitive advantage at the organizational level, which generalizes the findings of Calantone, Chan, and Cui (2006) and Sethi and Sethi (2009) from the individual product level. 
Our findings indicate that data-driven culture has a statistically significant moderating effect on the relationship between environmental scanning and new product meaningfulness. This suggests that there is a positive interaction between a data-driven culture and environmental scanning, which means that together they will have a stronger effect on new product meaningfulness. This seems to make sense as a firm's data-driven culture would encourage it to use insights gained from data while its environmental scanning provides the trends of customer demands; together they would enable the firm to better understand customers thereby to provide meaningful new products/services.

However, data-driven culture appears to have no statistically significant moderating effect on the relationship between environmental scanning and new product newness. It can be argued that environmental scanning for new product newness would depend on data about products, while environmental scanning for new product meaningfulness depends on data about products AND customers. That means the data input to new product newness is relatively simple while that to new product meaningfulness is always more complex, so the data-driven culture would help to strengthen the link between environmental scanning and new product meaningfulness.

It may not be so surprising that company size, industry type, respondent's job title and year of experience as control variables, as tested, have no effect on competitive advantage. Although there has been much research on using these variables as control variables to understand if they have an effect on innovation, the results so far appear to be contradictory and complex; McDermott and Prajogo (2012) even found that size moderated the effect of innovation on overall performance. This may suggest that it would not be possible to provide a conclusive result.

Our study makes a number of important contributions to research. Firstly, although a number of "white paper" articles and online reports claim that BA helps companies to innovate, there has been no theoretical understanding and empirical evidence to substantiate the claims. Our study has attempted to fill this research gap by linking BA to innovation with a cross-sectional perspective, supporting other works from the operational research community, which were based on case studies, e.g. Kunc and O'Brien (2018). This aim has been achieved by establishing a path model linking absorptive capacity, which includes BA, data-driven culture, and environmental scanning working together to acquire, assimilate and exploit external information, to new product innovation and competitive advantage. Datadriven culture has acted as a mediating factor between BA and environmental scanning as well as a specific culture factor moderating the path between environmental scanning and innovation. Our parsimonious model examines only how BA contributes to innovation based on the concept of a firm's absorptive capacity, thus providing researchers and practitioners with a specific and focused understanding of BA's impact. 
Secondly, focusing on wider evidence of BA's impact, our study makes original contributions by theorizing and confirming the positive effects of BA on data-driven culture and data-driven culture on environmental scanning. Our attempt to understand how BA applications enhance data-driven culture that in turn affects environmental scanning offers important insights into how BA's effect on environmental scanning has been enhanced indirectly through data-driven culture. The findings suggest that a datadriven culture can be significantly enhanced by BA applications and directly affect environmental scanning, supporting evidence provided by case studies in BA. This insight provides a deeper contextual understanding on the importance of data-driven culture and its critical role in enhancing BA's impact.

Thirdly, our findings demonstrate the pivotal role of environmental scanning in linking BA to innovation. It is important to note that our focus on environmental scanning as part of an organization's absorptive capacity is different from the concept of market orientation as a business strategy. Although some organizations such as Amazon embody both concepts, it is possible to have one without the other. For example, a market orientation strategy may be based on managers' "gut feel" rather than purposeful environmental scanning and data acquisition.

Finally, this study makes new contributions to our understanding of culture and innovation by focusing on the role of a specific organizational culture, which is data-driven culture, on new product innovation. Data-driven culture has attracted much attention from practitioners and researchers in recent years due to the increasing investment in Big Data and BA. However, there have been no previous attempts from researchers to theorize and empirically test if BA enhances data-driven culture and what role data-driven culture plays in product innovation.

\subsection{Managerial implications}

Our findings provide useful guidance for both managers and BA practitioners, to help them become more effective in achieving value from BA.

Firstly, the empirical evidence clearly demonstrates the important role of data-driven culture that can be regarded as an emergent organizational culture in the era of Big Data. Leaders can now depend less on their gut instincts and more on cultivating a data-driven culture and data-driven insights. Data-driven culture plays two important roles. One is to significantly enhance BA's impact on innovation via environmental scanning, improving the acquisition element of absorptive capacity. The other is its moderating effect on the relationship between environmental scanning and new product meaningfulness, improving assimilation and exploitation. This culture needs to cover all staff, not just BA practitioners, who from their background will probably adopt a data-driven culture anyway. Companies therefore should encourage staff to be open to new ideas and approaches that challenge their current practices on the basis of new information, to use data-based insights for the creation of new products/services, to 
identify and have data needs for decisions, to use evidence to support decision making, and most of all to believe the role and value of data and information in the organization. Additionally, companies should train staff, e.g. using MSc programmes in BA, on the appropriate aspects of Big Data and the use of analytics to generate data-based insights.

Secondly, companies should understand that installing BA tools alone in the workplace will not automatically generate new insights and knowledge and improve innovation; the challenge is to win the hearts and minds of the staff, not just make tools available. This cannot be left to the IT department, or a specialized data science/analytics group, whether associated with an OR group or not; it has to include, at minimum, everyone concerned with innovation. This risk of a specialized group becoming a consultancy that is called upon only too rarely is a familiar issue to those running OR groups (Liberatore \& Luo, 2010; Ranyard et al., 2015). BA practitioners need to realize that their work is not just the technical side of analysis, but also helping the rest of the organization to understand the meaning and significance of their findings, crucially including the assumptions and limitations of the analysis. This is, arguably, even more important if the BA practitioners provide so-called "self-service" BA tools for use by other staff. Specific staff to work as boundary spanners (Tushman, 1977) may be needed to help achieve this understanding, and BA practitioners and their managers need to recognize that the results, the assumptions and even the data may be contested.

Thirdly, although popular BA approaches such as CRISP-DM (Oztekin, Kizilaslan, Freund, \& Iseri, 2016; Shearer, 2000) are data-driven, the existence of data that is often taken for granted in literature on analytics may not be available in practice in companies. Pape (2016) presents a framework for prioritizing which data items to store, though the human resources example he gives is concerned entirely with internally-generated data, and the process-driven approach he offers would be likely to lead only to incremental change. Our findings indicate that BA influences data-driven culture, and both influence environmental scanning. This affects the relevance of and belief in the data that the organization chooses to acquire and process, whether through collection or purchase. Senior managers in particular need to ask "where are the data and analysis to support that?" when decisions are being made. However, there is a need to recognize that all data will not be Big Data and it may be unstructured (Kunc \& O'Brien, 2018) or even residing in the heads of many experts, such as the "data" for scenario generation in long term strategic planning processes, e.g. Willis, Cave, and Kunc (2018).

Fourthly, Vidgen et al. (2017) looked at the connection between data and value. Our work is complementary to theirs, in that ours looks at the connection between the BA activity and value. One of Vidgen et al's recommendations is "Becoming a data-driven organization will involve organizational and cultural change and innovation" (2017, p.633). Our research suggests that this cultural change also needs 
to encompass the importance of environmental scanning; a change in attitudes towards both internal and external data is needed.

Last, but not least, companies should understand that environmental scanning is the key enabler for BA to generate impact on product/service innovation. An insular attitude is most unlikely to bring innovation success. Generating better business intelligence with BA through environmental scanning facilitated by a strong data-driven culture will directly contribute to new product newness and meaningfulness. BA should be used to routinely understand opinions from clients, carry out special market research studies, explicitly monitor the policies and tactics of competitors, and forecast sales, customer preferences, technology, etc., as discussed in Kunc and O'Brien (2018).

\subsection{Limitations and future research}

The present study has a number of limitations. The respondents were all from firms in the UK. The model only focuses on BA's impact on innovation success based on absorptive capacity theory from an information processing and use perspective, thus it does not (and was not intended to) capture all the key factors affecting innovation success. Therefore, caution must be taken when applying the model to predict a company's innovation success because many other factors such as business strategy, management practices, human resource management, leadership, inter-firm networks, etc. may also influence innovation success, and the relationship may be different in other countries. Our data has only enabled us to use firm size, industry type, respondent's job title and year of experience as control variables, thus providing very limited analysis on the role of firm characteristics and innovation in the context of BA application. Future study should explore the effect of more in-depth firm characteristics, such as: R\&D spending, product diversity, collaboration with customers or suppliers, and revenue, on innovation outcome.

For size, our sample could not enable us to test for the most extreme differences because it did not cover small firms. It is possible that differences between small and large firms with regards to the use of BA may show a significant effect, due to the greater differences between them, so future research is needed to investigate if the research model is applicable to small firms. Caution should also be taken when

interpreting the effect of the control variables (e.g. industry types, respondent job title and years of job experience) due to the small sub-sample size.

The survey questionnaire was distributed via email using a well-known online survey tool, but this software is not able to detect and record how many emails have been distributed successfully to the intended recipient's inbox. As a result, this study is unable to provide an accurate value for response rate. This may raise concerns regarding self-selection bias. Although two tests were carried out, as reported in 
section 5.4, and found no evidence of non-respondent or self-selection bias, the risk of bias may still not be completely absent.

Finally, although our model captures BA's impact on new product/service innovation in terms of newness and meaningfulness, the low predictive power of the proposed model, especially in relation to new product meaningfulness, indicates there are other factors influencing a firm's innovation success not considered in our study. This suggests that the application of BA alone might not significantly transform a firm's innovation performance. Other factors must also be taken into account, so an integrated and coherent business strategy and approach for innovation success should always be considered.

Our study provides a number of directions for future research. Our model only focuses on new product/service innovation, not other areas of innovation, such as business process innovation or new business models. Future research should consider testing our model in other areas of innovation, or with other measures of business success, such as business survival and long-term sustainability. Researchers should also consider employing a qualitative approach, e.g. multiple case studies, to develop more indepth insight and knowledge on how BA adds value to organizations. A longitudinal study would also help researchers to trace the transformational change and associated impact over a period of time.

As for the relationship between BA and OR, two of the six areas in Mortenson et al. (2015)'s "research agenda for OR/MS in the analytics age" are "Incorporating unstructured data" and "Streaming data and real-time analytics" (p.592-3). Our study indicates that such research needs to include organizational and cultural aspects as well as purely technical or modeling ones: what structures, processes or initiatives would best encourage the necessary changes to happen? How is it possible to move from a single pilot BA/OR project to organization-wide use? Mixed qualitative and quantitative approaches are likely to be needed. Since organizational culture is not something that can easily be borrowed or imported, OR's expertise in problem structuring methods (Ranyard, Fildes and Hu, 2015) may be vital in helping an organization change its culture.

Equally, since it will never be possible to capture all data, especially with the advent of the Internet of Things, research into environmental scanning, especially data acquisition, then needs to build on work such as that of Pape (2016) to cater for more radical change: the processes that the organization might have in the future as well as those that it has now.

\section{Conclusion}

We believe that our study is the first to link BA to successful innovation, and evaluate how that link may operate, especially the roles of data-driven culture and environmental scanning.

The empirical evidence led to the conclusion that BA can improve a firm's innovation success in terms of new product newness and meaningfulness, thus leading to better competitive advantage. BA's impact can 
be achieved through a firm's absorptive capacity enabled by BA and effective information use for business intelligence through environmental scanning leading to better innovation.

Organizations that are eager to invest in BA and want to maximize its potential impact on innovation should pay particular attention to data-driven culture and environmental scanning, purposefully using BA to strengthen a data-driven culture and enhance environmental scanning effectiveness. Data-driven culture also helps a company to develop more meaningful new products using the insights generated with environmental scanning. The BA community can feel encouraged to promote the use of BA, as this study demonstrates its impact on innovation.

\section{References}

Abbasi, A., Sarker, S., \& Chiang, R. (2016). Big data research in information systems: Toward an inclusive research agenda. Journal of the Association for Information Systems, 17(2), i-xxxii.

Aguilar, F. J. (1967). Scanning the business environment: Macmillan.

Ahuja, G. (2000). Collaboration networks, structural holes, and innovation: A longitudinal study. Administrative science quarterly, 45(3), 425-455.

Amabile, T. M. (1983). The social psychology of creativity: A componential conceptualization. Journal of personality and social psychology, 45(2), 357.

Armstrong, C. P., \& Sambamurthy, V. (1999). Information Technology Assimilation in Firms: The Influence of Senior Leadership and IT Infrastructures. Information Systems Research, 10(4), 304327.

Armstrong, J. S., \& Overton, T. S. (1977). Estimating Nonresponse Bias in Mail Surveys. Journal of Marketing Research (JMR), 14(3), 396-402.

Atuahene-Gima, K. (1996). Market orientation and innovation. Journal of Business Research, 35(2), 93103. doi:http://dx.doi.org/10.1016/0148-2963(95)00051-8

Augusto, M., \& Coelho, F. (2009). Market orientation and new-to-the-world products: Exploring the moderating effects of innovativeness, competitive strength, and environmental forces. Industrial Marketing Management, 38(1), 94-108.

Bagozzi, R. P., Youjae, Y., \& Phillips, L. W. (1991). Assessing Construct Validity in Organizational Research. Administrative science quarterly, 36(3), 421-458.

Baregheh, A., Rowley, J., \& Sambrook, S. (2009). Towards a multidisciplinary definition of innovation. Management decision, 47(8), 1323-1339.

Barney, J. B. (1986). Organizational culture: can it be a source of sustained competitive advantage? Academy of Management Review, 11(3), 656-665.

Baron, R. M., \& Kenny, D. A. (1986). The Moderator-Mediator Variable Distinction in Social Psychological Research - Conceptual, Strategic, and Statistical Considerations. Journal of personality and social psychology, 5(6), 1173-1182.

Barton, D., \& Court, D. (2012). Making Advanced Analytics Work For You. Harvard Business Review, 90(10), 78-83.

Bourgeois, L. J. (1980). Strategy and environment: A conceptual integration. Academy of Management Review, 5(1), 25-39.

Büschgens, T., Bausch, A., \& Balkin, D. B. (2013). Organizational Culture and Innovation: A Meta Analytic Review. Journal of Product Innovation Management, 30(4), 763-781.

Calantone, R. J., Chan, K., \& Cui, A. S. (2006). Decomposing product innovativeness and its effects on new product success. Journal of Product Innovation Management, 23(5), 408-421. 
Chen, H., Chiang, R. H. L., \& Storey, V. C. (2012). Business intelligence and analytics: from big data to big impact. MIS Quarterly, 36(4), 1165-1188.

Chen, P.-C., \& Hung, S.-W. (2014). Collaborative green innovation in emerging countries: a social capital perspective. International Journal of Operations \& Production Management, 34(3), 347-363.

Chen, Y.-S., Lin, M.-J. J., \& Chang, C.-H. (2009). The positive effects of relationship learning and absorptive capacity on innovation performance and competitive advantage in industrial markets. Industrial Marketing Management, 38(2), 152-158.

Choi, K., Narasimhan, R., \& Kim, S. W. (2016). Opening the technological innovation black box: The case of the electronics industry in Korea. European Journal of Operational Research, 250(1), 192-203.

Choo, C. W. (1999). The art of scanning the environment. Bulletin of the Association for Information Science and Technology, 25(3), 21-24.

Cohen, W. M., \& Levinthal, D. A. (1990). Absorptive capacity: a new perspective on learning and innovation. Administrative science quarterly, 15(1), 128-152.

Cooper, R. G. (1979). The dimensions of industrial new product success and failure. The Journal of Marketing, 43(3), 93-103.

Cooper, R. G., Easingwood, C. J., Edgett, S., Kleinschmidt, E. J., \& Storey, C. (1994). What Distinguishes the Top Performing New Products in Financial Services. Journal of Product Innovation Management, 11(4), 281-299.

Cuellar, M. J., \& Gallivan, M. J. (2006). A framework for ex ante project risk assessment based on absorptive capacity. European Journal of Operational Research, 173(3), 1123-1138.

Dahlander, L., \& Gann, D. M. (2010). How open is innovation? Research Policy, 39(6), 699-709.

Davenport, T. H. (2006). Competing on analytics. Harvard Business Review, 84(1), 98-107.

Davenport, T. H. (2013). Analytics 3.0. Harvard Business Review, 91(12), 64-72.

Davenport, T. H., \& Harris, J. G. (2007). Competing on analytics: The new science of winning. Boston, MA: Harvard Business School Review Press.

Davenport, T. H., Harris, J. G., De Long, D. W., \& Jacobson, A. L. (2001). Data to Knowledge to Results: Building an Analytic Capability. California Management Review, 43(2), 117-138.

Delen, D., \& Demirkan, H. (2013). Data, information and analytics as services. Decision Support Systems, 55(1), 359-363.

DeLone, W. H., \& McLean, E. R. (2003). The DeLone and McLean Model of Information Systems Success: A Ten-Year Update. Journal of Management Information Systems, 19(4), 9-30.

Droge, C., Calantone, R., \& Harmancioglu, N. (2008). New Product Success: Is It Really Controllable by Managers in Highly Turbulent Environments? Journal of Product Innovation Management, 25(3), 272-286. doi:10.1111/j.1540-5885.2008.00300.x

Dutta, D., \& Bose, I. (2015). Managing a Big Data project: The case of Ramco Cements Limited. International Journal of Production Economics, 165(3), 293-306. doi:http://dx.doi.org/10.1016/j.ijpe.2014.12.032

Erdogan, B., Liden, R. C., \& Kraimer, M. L. (2006). Justice and leader-member exchange: The moderating role of organizational culture. Academy of Management Journal, 49(2), 395-406.

Evanschitzky, H., Eisend, M., Calantone, R. J., \& Jiang, Y. (2012). Success Factors of Product Innovation: An Updated Meta-Analysis Journal of Product Innovation Management, 29(S1), 2137. doi:10.1111/j.1540-5885.2012.00964.x

Fitzgerald, B., \& O'Kane, T. (1999). A longitudinal study of software process improvement. IEEE Software, 16(3), 37-45.

Frishammar, J., \& Åke Hörte, S. (2005). Managing External Information in Manufacturing Firms: The Impact on Innovation Performance. Journal of Product Innovation Management, 22(3), 251-266.

Gillon, K., Aral, S., Ching-Yung, L., Mithas, S., \& Zozulia, M. (2014). Business analytics: radical shift or incremental change? Communications of the Association for Information Systems, 34(1), 287296. 
Glazer, R. (1991). Marketing in an information-intensive environment: strategic implications of knowledge as an asset. The Journal of Marketing, 1-19.

Goes, P. B. (2014). Big data and IS research. MIS Quarterly, 38(3), iii-viii.

Hair, J. F., Black, W. C., Babin, B. J., \& Anderson, R. E. (2010). Multivariate Data Analysis (7 ${ }^{\text {th }}$ ed.). New Jersey: Pearson Prentice Hall.

Hair, J. F., Hult, G., Ringle, C., \& Sarstedt, M. (2014). A Primer on Partial Least Squares Structural Equation Modeling (PLS-SEM): Sage.

Hair, J. F., Ringle, C. M., \& Sarstedt, M. (2013). Partial Least Squares Structural Equation Modeling: Rigorous Applications, Better Results and Higher Acceptance. Long Range Planning, 46(1-2), 112. doi:10.1016/j.lrp.2013.01.001

Hambrick, D. C. (1982). Environmental scanning and organizational strategy. Strategic Management Journal, 3(2), 159-174.

Harris, S. L., May, J. H., \& Vargas, L. G. (2016). Predictive analytics model for healthcare planning and scheduling. European Journal of Operational Research, 253(1), 121-131.

Herrera, M. E. B. (2015). Creating competitive advantage by institutionalizing corporate social innovation. Journal of Business Research, 68(7), 1468-1474. doi:http://dx.doi.org/10.1016/j.jbusres.2015.01.036

Higgins, J. M., \& McAllaster, C. (2002). Want Innovation? Then Use Cultural Artifacts that Support It. Organizational Dynamics, 31(1), 74-84. doi:http://dx.doi.org/10.1016/S0090-2616(02)00073-6

Hindle, G. A., \& Vidgen, R. (2017). Developing a business analytics methodology: a case study in the foodbank sector. European Journal of Operational Research.

Holsapple, C., Lee-Post, A., \& Pakath, R. (2014). A unified foundation for business analytics. Decision Support Systems, 64, 130-141. doi:http://dx.doi.org/10.1016/j.dss.2014.05.013

Hong, J., Song, T. H., \& Yoo, S. (2013). Paths to Success: How Do Market Orientation and Entrepreneurship Orientation Produce New Product Success? Journal of Product Innovation Management, 30(1), 44-55. doi:10.1111/j.1540-5885.2012.00985.x

Hurley, R. F., \& Hult, G. T. M. (1998). Innovation, market orientation, and organizational learning: an integration and empirical examination. The Journal of Marketing, 62(3), 42-54.

Im, S., \& Workman Jr, J. P. (2004). Market Orientation, Creativity, and New Product Performance in High-Technology Firms. Journal of Marketing, 68(2), 114-132.

Joshi, K. D., Chi, L., Datta, A., \& Han, S. (2010). Changing the competitive landscape: Continuous innovation through IT-enabled knowledge capabilities. Information Systems Research, 21(3), 472-495.

Kearns, G., \& Sabherwal, R. (2007). Strategic Alignment Between Business and Information Technology: A Knowledge-Based View of Behaviors, Outcome, and Consequences. Journal of Management Information Systems, 23(3), 129-162.

Keller, R. T., \& Holland, W. E. (1975). Boundary-spanning roles in a research and development organization: An empirical investigation. Academy of Management Journal, 18(2), 388-393.

Kianto, A., Andreeva, T., \& Pavlov, Y. (2013). The impact of intellectual capital management on company competitiveness and financial performance. Knowledge Management Research \& Practice, 11(2), 112-122.

Kim, N., Im, S., \& Slater, S. F. (2013). Impact of Knowledge Type and Strategic Orientation on New Product Creativity and Advantage in High-Technology Firms Impact of Knowledge Type and Strategic Orientation on New Product Creativity and Advantage in High-Technology Firms. Journal of Product Innovation Management, 30(1), 136-153. doi:10.1111/j.15405885.2012.00992.X

Kiron, D., Ferguson, R. B., \& Prentice, P. K. (2013). From value to vision: Reimagining the possible with data analytics. MIT Sloan Management Review, 54(3), 1-19.

Kiron, D., Prentice, P. K., \& Ferguson, R. B. (2012). Innovating with analytics. MIT Sloan Management Review, 54(1), 47-52. 
Kiron, D., \& Shockley, R. (2011). Creating business value with analytics. MIT Sloan Management Review, 53(1), 57-63.

Krosnick, J. A. (1999). Survey research. Annual Review of Psychology, 50(1), 537.

Kunc, M., \& O'Brien, F. A. (2018). The role of business analytics in supporting strategy processes: Opportunities and limitations. Journal of the Operational Research Society, Advance Online Publication. doi:10.1080/01605682.2018.1475104

Lau, R. Y., Liao, S. S., Wong, K.-F., \& Chiu, D. K. (2012). Web 2.0 environmental scanning and adaptive decision support for business mergers and acquisitions. MIS Quarterly, 1239-1268.

Lavalle, S., Lesser, E., Shockley, R., Hopkins, M. S., \& Kruschwitz, N. (2011). Special Report: Analytics and the New Path to Value. MIT Sloan Management Review, 52(2), 22-32.

Leal-Rodríguez, A. L., Ariza-Montes, J. A., Roldán, J. L., \& Leal-Millán, A. G. (2014). Absorptive capacity, innovation and cultural barriers: A conditional mediation model. Journal of Business Research, 67(5), 763-768. doi:http://dx.doi.org/10.1016/j.jbusres.2013.11.041

Lengnick-Hall, C. A. (1992). Innovation and competitive advantage: What we know and what we need to learn. Journal of Management, 18(2), 399-429.

Li, Y., Thomas, M. A., \& Osei-Bryson, K.-M. (2016). A snail shell process model for knowledge discovery via data analytics. Decision Support Systems, 91, 1-12.

Liberatore, M. J., \& Luo, W. (2010). The analytics movement: Implications for operations research. Interfaces, 40(4), 313-324.

Little, R. J. (1988). A test of missing completely at random for multivariate data with missing values. Journal of the American Statistical Association, 83(404), 1198-1202.

Maier, J. L., Rainer Jr, R. K., \& Snyder, C. A. (1997). Environmental scanning for information technology: an empirical investigation. Journal of Management Information Systems, 14(2), 177200.

Malhotra, N. K., Patil, A., \& Kim, S. S. (2007). BIAS Breakdown. Marketing Research, 19(1), 24-29.

McDermott, C. M., \& Prajogo, D. I. (2012). Service innovation and performance in SMEs. International Journal of Operations \& Production Management, 32(2), 216-237.

Miller, D., \& Friesen, P. H. (1982). Innovation in Conservative and Entrepreneurial Firms: Two Models of Strategic Momentum. Strategic Management Journal, 3(1), 1-25.

Mohr, D. C., Young, G. J., \& Burgess, J. J. F. (2012). Employee turnover and operational performance: the moderating effect of group-oriented organisational culture. Human Resource Management Journal, 22(2), 216-233. doi:10.1111/j.1748-8583.2010.00159.x

Mortenson, M. J., Doherty, N. F., \& Robinson, S. (2015). Operational research from Taylorism to Terabytes: A research agenda for the analytics age. European Journal of Operational Research, 241(3), 583-595.

Nagati, H., \& Rebolledo, C. (2012). The role of relative absorptive capacity in improving suppliers' operational performance. International Journal of Operations \& Production Management, 32(5), 611-630.

Najafi Tavani, S., Sharifi, H., \& S. Ismail, H. (2013). A study of contingency relationships between supplier involvement, absorptive capacity and agile product innovation. International Journal of Operations \& Production Management, 34(1), 65-92.

Nonaka, I., \& Takeuchi, H. (1995). The knowledge-creating company: How Japanese companies create the dynamics of innovation: Oxford university press.

O'Brien, F. A., \& Dyson, R. G. (2007). Supporting strategy: frameworks, methods and models. Chichester: John Wiley \& Sons.

Ottum, B. D., \& Moore, W. L. (1997). The role of market information in new product success/failure. Journal of Product Innovation Management, 14(4), 258-273. doi:http://dx.doi.org/10.1016/S0737-6782(97)00013-1

Oztekin, A., Kizilaslan, R., Freund, S., \& Iseri, A. (2016). A data analytic approach to forecasting daily stock returns in an emerging market. European Journal of Operational Research, 253(3), 697710. 
Pan, X., \& Li, S. (2016). Dynamic optimal control of process-product innovation with learning by doing. European Journal of Operational Research, 248(1), 136-145.

Pape, T. (2016). Prioritising data items for business analytics: Framework and application to human resources. European Journal of Operational Research, 252(2), 687-698.

Petter, S., Straub, D., \& Rai, A. (2007). Specifying formative constructs in information systems research. MIS Quarterly, 31(4), 623-656.

Podsakoff, P. M., MacKenzie, S. B., \& Podsakoff, N. P. (2012). Sources of Method Bias in Social Science Research and Recommendations on How to Control It. Annual Review of Psychology, 63(1), 539-569. doi:10.1146/annurev-psych-120710-100452

Porter, M. E., \& Millar, V. E. (1985). How information gives you competitive advantage. Harvard Business Review, 63(4), 149-160.

Ranyard, J. C., Fildes, R., \& Hu, T.-I. (2015). Reassessing the scope of OR practice: The influences of problem structuring methods and the analytics movement. European Journal of Operational Research, 245(1), 1-13.

Rehm, S.-V., \& Goel, L. (2015). The emergence of boundary clusters in inter-organizational innovation. Information and Organization, 27-51. doi:http://dx.doi.org/10.1016/j.infoandorg.2014.12.001

Ritala, P., \& Hurmelinna - Laukkanen, P. (2013). Incremental and radical innovation in coopetition-The role of absorptive capacity and appropriability. Journal of Product Innovation Management, 30(1), 154-169.

Robinson, A., Levis, J., \& Bennett, G. (2010). INFORMS to officially join analytics movement. $O R / M S$ Today, 37(5), 59.

Royston, G. (2013). Operational Research for the Real World: big questions from a small island. Journal of the Operational Research Society, 64(6), 793-804.

Schein, E. H. (1990). Organizational culture (Vol. 45): American Psychological Association.

Sethi, R., \& Sethi, A. (2009). Can Quality - Oriented Firms Develop Innovative New Products? Journal of Product Innovation Management, 26(2), 206-221.

Shearer, C. (2000). The CRISP-DM model: the new blueprint for data mining. Journal of data warehousing, 5(4), 13-22.

Shrout, P. E., \& Bolger, N. (2002). Mediation in experimental and nonexperimental studies: New procedures and recommendations. Psychological Methods, 7(4), 422-445. doi:10.1037/1082989x.7.4.422

Stock, R. M., \& Zacharias, N. A. (2013). Two sides of the same coin: How do different dimensions of product program innovativeness affect customer loyalty? Journal of Product Innovation Management, 30(3), 516-532.

Stuart, T. E. (2000). Interorganizational Alliances and the Performance of Firms: A Study of Growth and Innovation Rates in a High-Technology Industry. Strategic Management Journal, 21(8), 791-811.

Stubbs, E. (2014). Big Data, Big Innovation: Enabling Competitive Differentiation through Business Analytics: John Wiley \& Sons.

Subramaniam, M., \& Youndt, M. A. (2005). The Influence of Intellectual Capital on the Types of Innovation Capabilities. Academy of Management Journal, 48(3), 450-463.

Sumo, R., van der Valk, W., Bode, C., \& van Weele, A. (2016). Fostering incremental and radical innovation through performance-based contracting in buyer-supplier relationships. International Journal of Operations and Production Management, 36(11), 1482-1503.

Tambe, P. (2014). Big data investment, skills, and firm value. Management Science, 60(6), 1452-1469.

Thayer, L. O. (1968). Communication and communication systems in organization, management, and interpersonal relations: Homewood (Ill.) Irwin.

Thompson, V. A. (1965). Bureaucracy and innovation. Administrative science quarterly, 10(1), 1-20.

Tushman, M. L. (1977). Special boundary roles in the innovation process. Administrative science quarterly, 22(4), 587-605. 
Van Riel, A. C., Lemmink, J., \& Ouwersloot, H. (2004). High - Technology Service Innovation Success: A Decision - Making Perspective. Journal of Product Innovation Management, 21(5), 348-359.

Verbraken, T., Verbeke, W., \& Baesens, B. (2014). Profit optimizing customer churn prediction with Bayesian network classifiers. Intelligent Data Analysis, 18(1), 3-24.

Vidgen, R., Shaw, S., \& Grant, D. B. (2017). Management challenges in creating value from business analytics. European Journal of Operational Research, 261(2), 626-639.

Watson, H. J. (2014). Tutorial: big data analytics: concepts, technologies, and applications. Communications of the Association for Information Systems, 34(1), 1247-1268.

Wedel, M., \& Kannan, P. (2016). Marketing Analytics for Data-Rich Environments. Journal of Marketing, 80(6), 97-122.

Willis, G., Cave, S., \& Kunc, M. (2018). Strategic workforce planning in healthcare: A multimethodology approach. European Journal of Operational Research, 267(1), 253-263.

Wyld, D. C., \& Maurin, R. (2009). Keys to Innovation: The Right Measures and the Right Culture? The Academy of Management Perspectives, 23(2), 96-98.

Zahra, S. A., \& George, G. (2002). Absorptive capacity: A review, reconceptualization, and extension. Academy of Management Review, 27(2), 185-203.

Zahra, S. A., Sapienza, H. J., \& Davidsson, P. (2006). Entrepreneurship and Dynamic Capabilities: A Review, Model and Research Agenda. Journal of Management Studies, 43(4), 917-955. doi:10.1111/j.1467-6486.2006.00616.x

Zhang, M., Zhao, X., Lyles, M. A., \& Guo, H. (2015). Absorptive capacity and mass customization capability. International Journal of Operations \& Production Management, 35(9), 1275-1294. 